\title{
Basic fibroblast growth factor as a potential biomarker for diagnosing malignant tumor metastasis in women
}

\author{
MAN LIU and LU-QI XING \\ Department of Pathology, The First Affiliated Hospital of Henan University of Science and Technology, \\ Luoyang, Henan 471003, P.R. China
}

Received October 27, 2015; Accepted April 13, 2017

DOI: $10.3892 / \mathrm{ol} .2017 .6335$

\begin{abstract}
Previous studies have reported that basic fibroblast growth factor (bFGF) is associated with tumor genesis, growth and prognosis. The present study was conducted to detect the levels of bFGF expression in women with non-small cell lung cancer (NSCLC), colon cancer, breast cancer and melanoma, and analyze its association with the clinicopathological characteristics of malignant tumors. The tumor tissues were obtained from 508 female patients with malignant tumors between March 2008 and May 2015 (103 NSCLC, 147 colon cancer, 206 breast cancer and 52 melanoma). Histological examination was performed on paraffin-embedded tissues. The immunohistochemical peroxidase-conjugated streptavidin method was used to detect bFGF protein expression in the tissues. The level of bFGF protein expression was significantly increased in patients with NSCLC with poor differentiation and lymph node metastasis compared with patients with moderately/well differentiated NSCLC without lymph node metastasis. Increased levels of bFGF protein expression were observed in patients with colon cancer with lymph node metastasis compared with patients without lymph node metastasis, and in patients with breast cancer with tumor-node-metastasis stage III-IV and lymph node metastasis compared with patients in stage I-II and without lymph node metastasis. The rate of positive bFGF staining in patients with melanoma with lymph node metastasis was significantly higher compared with patients without lymph node metastasis. These results suggested that bFGF may be associated with the process of malignant tumor genesis and growth, and the expression of bFGF protein may be a potential and effective biomarker for diagnosing malignant tumor metastasis in females. The present study may also provide theoretical bases
\end{abstract}

Correspondence to: Dr Man Liu, Department of Pathology, The First Affiliated Hospital of Henan University of Science and Technology, 24 Jinghua Road, Luoyang, Henan 471003, P.R. China E-mail:manliuuu@126.com

Key words: basic fibroblast growth factor, non-small cell lung cancer, colon cancer, breast cancer, melanoma, malignant tumor for the clinical application of bFGF monoclonal antibody in molecular targeted therapies in tumors.

\section{Introduction}

Previous studies have reported that high expression of basic fibroblast growth factor (bFGF) is associated with tumor genesis, growth and prognosis $(1,2)$. bFGF may affect the proliferation and differentiation of a number of cell types in vitro, including neural stem cells (3). The bFGF is a type of polypeptide growth factor, which are produced via cell proliferation in the mesoderm and neural ectoderm (4). The most significant biological function of bFGF reported is to promote proliferation (5). In pathological cases, bFGF is involved in tumor genesis, growth and promoting the repair of damaged issues (5). bFGF and its receptors in tumor tissue are potential targets for antitumor therapy (6). Targeting anti-bFGF antibodies and fibroblast growth factor receptor (FGFR) antagonists may inhibit tumor cell proliferation and metastasis as well as block the blood supply for tumor growth and metastasis (6).

bFGF is reported to be involved in tumor genesis and growth through two mechanisms as follows: i) Promotion of overproliferation of tumor cells in an autocrine or paracrine manner; and ii) promotion of tumor angiogenesis to provide nutrients for tumor cell growth, which is the main route by which bFGF is involved in the pathological process of tumors (7). bFGF is a major pro-angiogenic factor during tumor angiogenesis. In normal tissues, bFGF expression is absent, or it is detected at low levels. By contrast, the level of bFGF expression level is high in tumor issues (8). bFGF is also an important factor involved in tumor growth and invasion, and is involved in the genesis and growth of a variety of malignant tumors, including breast cancer, lung cancer and prostate cancer $(9,10)$.

Previous studies have investigated the expression level of bFGF in advance NSCLC cell lines $(11,12)$. However, the limitations of these studies were evident. These studies used relatively small sample sizes and investigated only a single type of tumor. In addition, sex-based differences were not taken into consideration. Therefore, in the present study, 508 female patients with malignant tumors [103 non-small cell lung cancer (NSCLC), 147 colon cancer, 206 breast cancer and 52 melanoma] were recruited to study the level of bFGF expression in tumor cells, and to investigate the association 
between expression level of bFGF protein and clinicopathological characteristics of malignant tumors.

\section{Patients and methods}

Female patients. Prior to recruiting female patients, approval to conduct the present study was obtained from the Ethics Committee of Henan University of Science and Technology (Henan, China). Written informed consent was obtained from all patients. Female patients with one of the following malignant tumors were included between March 2008 and May 2015: NSCLC, colon cancer, breast cancer and melanoma. Patients that received radiotherapy, chemotherapy or traditional Chinese medicine treatment prior to surgery were excluded. All patients were diagnosed by pathological or clinical method. Finally, a total of 103 patients with NSCLC, 147 patients with colon cancer, 206 patients with breast cancer and 52 patients with melanoma were recruited in the present study.

Immunohistochemical staining. The tumor tissues from the female patients were obtained by standard method (routine examination) and embedded in paraffin (4\% paraformaldehyde for $24 \mathrm{~h}$ at room temperature). The paraffin-embedded tumor tissues were serially cut for histological examination. A total of two sections (thickness, $5 \mu \mathrm{m}$ ) were randomly selected from each patient. Hematoxylin-eosin staining was performed at room temperature for $24 \mathrm{~h}$ on one section for histomorphometric observations. The tissue sections were subjected to dewaxing, dehydration (descending alcohol series) and washing with PBS, and subsequently treated with hematoxylin for 10-15 min at $60^{\circ} \mathrm{C}, 5 \%$ hydrochloric acid in ethanol for several sec subsequent to washing in running water. The tissue sections were re-stained with eosin for $5 \mathrm{~min}$ at room temperature, dehydrated by graded alcohol and treated with mounting medium (Nanjing KeyGen Biotech Co., Ltd., Nanjing, China). Olympus PM 20 (Olympus Corporation, Tokyo, Japan) was used to capture images (magnification, x100). The immunohistochemical peroxidase-conjugated streptavidin method was performed on the other section to detect the expression level of bFGF protein in tumor tissues using an SP immunohistochemistry kit (rabbit) supplied by Nanjing KeyGen Biotech Co., Ltd. PBS was used as the negative control to replace the primary antibody. Goat serum (KGIHC008; Nanjing KeyGen Biotech Co., Ltd.) was applied at $4^{\circ} \mathrm{C}$ overnight to block non-specific binding. The anti-bFGF rabbit polyclonal antibody (dilution, 1:200; KGIHC009; Nanjing KeyGen Biotech Co., Ltd.) was used at $4^{\circ} \mathrm{C}$ overnight. Then a horseradish peroxidase-conjugated sheep anti-rabbit secondary antibody (dilution, 1:200; KGIHC011; Nanjing KeyGen Biotech Co., Ltd.) was applied at room temperature for $1 \mathrm{~h}$. The Image-Pro Plus 6.0 (Media Cybernetics, Inc., Rockville, MD, USA) was used to measure the density.

Scoring of immunostaining. Positive bFGF protein expression in tumor tissues was identified by the presence of yellow-brown granules in the tumor cell cytoplasm. The immunoreactivity was semi-quantitatively scored using the intensity of the immunostaining and the percentage of tumor cells with positive bFGF expression, as described previously (13). Positive percentage was graded as $0(<10 \%$ positive tumor cells), 1 (10-24\%), 2 (25-49\%), $3(50-75 \%)$ and $4(>75 \%)$.
The intensity of the immunostaining was graded as 0 (no immunoreactivity), 1 (weak intensity), 2 (moderate intensity) and 3 (strong intensity). The two scores were subsequently added and scored as follows: $>5$, strong expression (+++); 4-5, as moderate expression (++); 2-3, weak expression (+); and 0-1, absent expression (-).

Statistical analysis. The continuous data are expressed as the mean \pm standard deviation, and the numerical data are expressed as the number and percentage. Student's t-test and one-way analysis of variance were used when appropriate. Ranked data were evaluated by Kruskal-Wallis test for multiple group comparisons and Nemenyi test for comparisons between two groups. If a significant difference was found, a Bonferroni post hoc test was performed. $\mathrm{P}<0.05$ was considered to indicate a statistically significant difference. SPSS version 19.0 was used to perform all analysis (IBM Corp., Armonk, NY, USA).

\section{Results}

bFGF protein expression in NSCLC. In total, 103 patients with NSCLC were included in the present study. The mean age of these patients was 54.3 years (range, $35-75$ years). Of these patients, $\sim 70 \%$ were married, $62.3 \%$ were non-smokers and $66.4 \%$ received $\leq 9$ years education. Among the married patients, the percentage of smoking in husbands of these patients was $85.4 \%$. According to the tumor-node-metastasis (TNM) stage (14), a total of 24 patients were in stage I, 25 were in stage II and 54 were in stage III/IV. Among these patients, there were 71 patients with lymph node metastasis, and 64 patients with poor differentiation. The total rate of positive bFGF staining in NSCLC tissues was $64.1 \%$ (66/103). The rate of positive bFGF staining in NSCLC with poor differentiation tissues was significantly increased compared with patients with moderately/well differentiated NSCLC $(\mathrm{P}=0.00023)$. Compared with patients without lymph node metastasis, patients with lymph node metastasis had a significantly increased rate of positive bFGF staining ( $\mathrm{P}=0.00025$; Table I; Fig. 1).

bFGF protein expression in colon cancer. A total of 147 patients with colon cancer were included in the present study. The mean age of these patients was 46.3 years (range, 33-61 years). Of these patients, $73 \%$ were married, $69.5 \%$ were non-smoker patients and $60.3 \%$ received $\leq 9$ years education. According to the TNM staging system (14), 44 patients were in stage I, 55 were in stage II and 48 were in stage III/IV. Among these patients, there were 105 patients with lymph node metastasis and 80 patients with poor differentiation. The rate of positive bFGF staining in patients with colon cancer was $60.5 \%$ (89/147). The rate of positive bFGF staining in patients with colon cancer with lymph node metastasis was significantly higher compared with patients without lymph node metastasis ( $\mathrm{P}=0.00001$; Table II; Fig. 2).

bFGF protein expression in breast cancer. In total, 206 patients with breast cancer were included in the present study. The mean age of these patients was 52.6 years (range, 38-56 years). Of these patients, $\sim 62.7 \%$ were married, $65.3 \%$ were non-smoker patients and $63.8 \%$ received $\leq 9$ years education. According to the TNM staging system (14), 59 patients were in stage I, 
Table I. bFGF protein expression in patients with non-small cell lung cancer.

\begin{tabular}{|c|c|c|c|c|c|c|c|}
\hline \multirow[b]{2}{*}{ Variable } & \multirow[b]{2}{*}{$\mathrm{n}$} & \multicolumn{4}{|c|}{ bFGF expression, $\mathrm{n}$} & \multirow{2}{*}{$\begin{array}{l}\text { Positive } \\
\text { rate, \% }\end{array}$} & \multirow[b]{2}{*}{ P-value } \\
\hline & & - & + & ++ & +++ & & \\
\hline Differentiation & & & & & & & 0.00023 \\
\hline Poor & 64 & 13 & 10 & 25 & 16 & 79.7 & \\
\hline Moderate/well & 39 & 24 & 9 & 5 & 1 & 38.5 & \\
\hline TNM stage & & & & & & & 0.77827 \\
\hline I & 24 & 10 & 8 & 4 & 2 & 58.3 & \\
\hline II & 25 & 9 & 8 & 6 & 2 & 64.0 & \\
\hline III/IV & 54 & 18 & 20 & 11 & 5 & 66.7 & \\
\hline Lymph node metastasis & & & & & & & 0.00025 \\
\hline Yes & 71 & 16 & 9 & 21 & 25 & 77.5 & \\
\hline No & 32 & 21 & 8 & 3 & 0 & 34.4 & \\
\hline
\end{tabular}

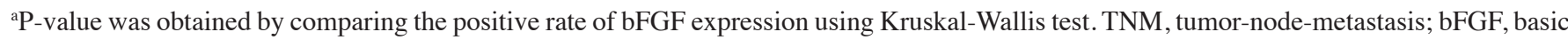
fibroblastic growth factor.
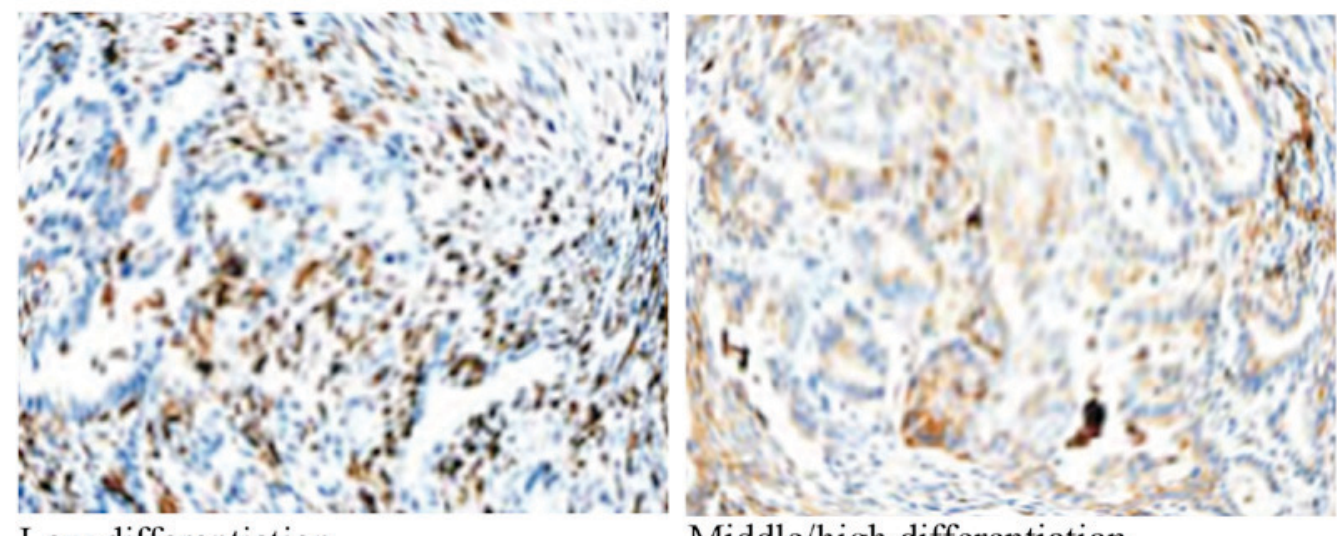

Low differentiation

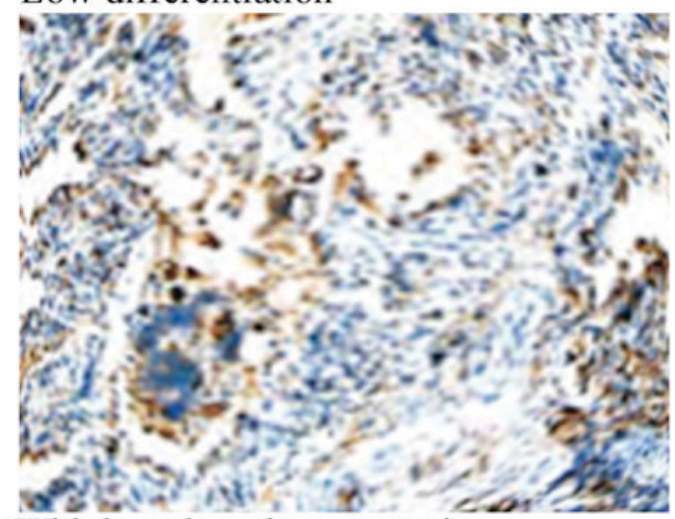

With lymph node metastasis

\section{Middle/high differentiation}

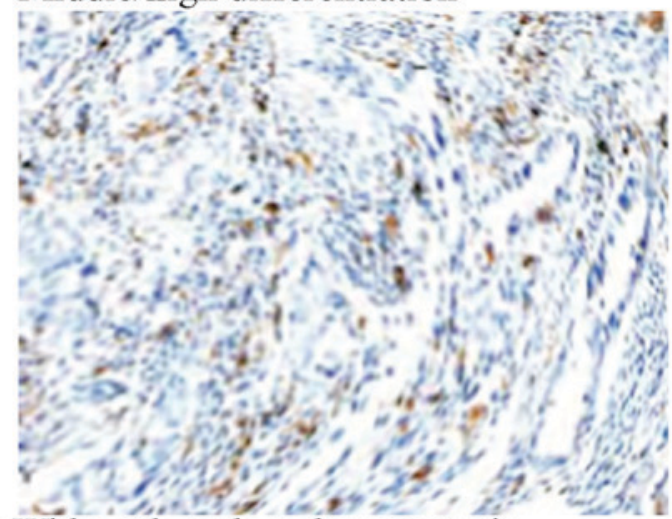

Without lymph node metastasis

Figure 1. Representative image of immunohistochemical staining of basic fibroblastic growth factor in tumor tissues obtained from patients with non-small cell lung cancer (magnification, x100).

48 were in stage II and 99 were in stage III/IV. Among these patients, there were 134 patients with lymph node metastasis and 118 patients with poor differentiation. The total rate of positive bFGF staining in breast cancer was $71.8 \%(148 / 206)$. The positive rate in patients with breast cancer with lymph node metastasis was significantly higher compared with patients without lymph node metastasis $(\mathrm{P}<0.00001)$. Compared with patients in stage I-II, patients in stage III/IV had a significantly higher rate of positive staining ( $\mathrm{P}=0.00001$; Table III; Fig. 3).

bFGF protein expression in melanoma. In total, 52 patients with melanoma were included in the present study. The average 
Table II. bFGF protein expression in patients with colon cancer.

\begin{tabular}{|c|c|c|c|c|c|c|c|}
\hline \multirow[b]{2}{*}{ Variable } & \multirow[b]{2}{*}{$\mathrm{n}$} & \multicolumn{4}{|c|}{ bFGF expression, $\mathrm{n}$} & \multirow{2}{*}{$\begin{array}{l}\text { Positive } \\
\text { rate, } \%\end{array}$} & \multirow[b]{2}{*}{ P-value ${ }^{a}$} \\
\hline & & - & + & ++ & +++ & & \\
\hline Differentiation & & & & & & & 0.22727 \\
\hline Poor & 80 & 28 & 13 & 27 & 12 & 65.0 & \\
\hline Moderate/well & 67 & 30 & 8 & 21 & 8 & 55.2 & \\
\hline TNM stage & & & & & & & 0.83647 \\
\hline I & 44 & 18 & 8 & 14 & 4 & 59.1 & \\
\hline II & 55 & 20 & 11 & 18 & 6 & 63.6 & \\
\hline III/IV & 48 & 20 & 7 & 16 & 5 & 58.3 & \\
\hline Lymph node metastasis & & & & & & & 0.00001 \\
\hline Yes & 105 & 29 & 19 & 25 & 32 & 72.4 & \\
\hline No & 42 & 28 & 9 & 5 & 0 & 33.3 & \\
\hline
\end{tabular}

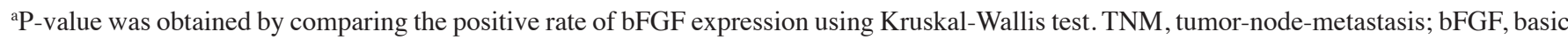
fibroblastic growth factor.

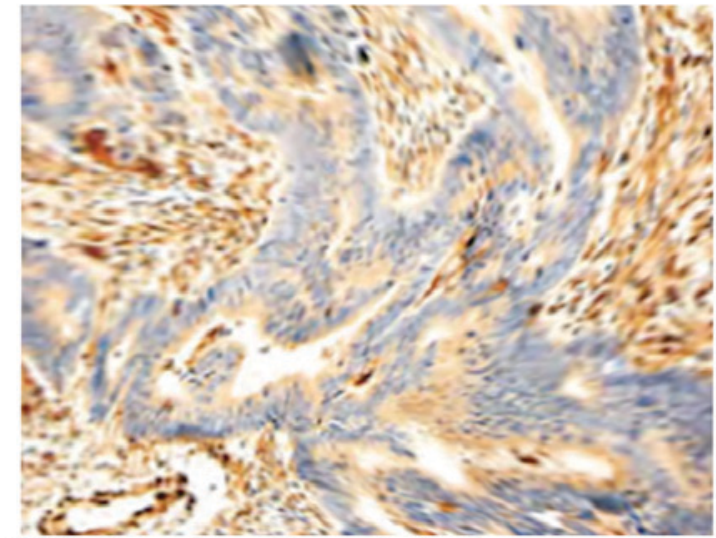

With lymph node metastasis

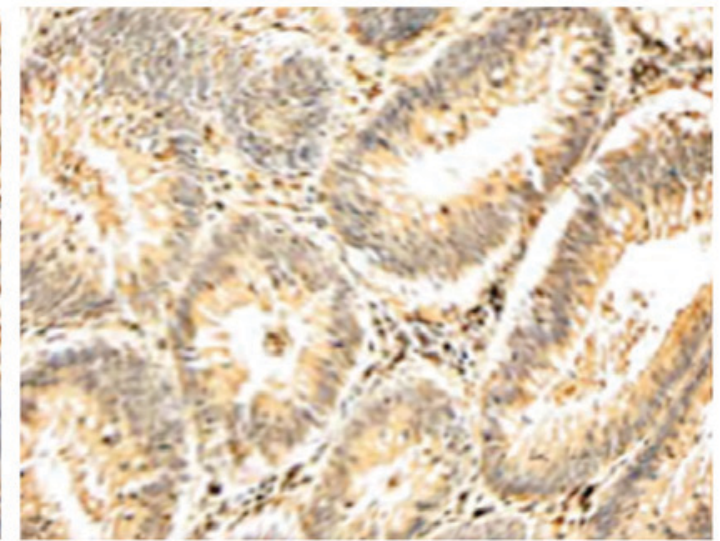

Without lymph node metastasis

Figure 2. Representative image of immunohistochemical staining of basic fibroblastic growth factor in tumor tissues obtained from patients with colon cancer (magnification, x100).

age of these patients was 55.8 years (range, $40-63$ years). Of these patients, $\sim 71.0 \%$ were married, $69.4 \%$ were non-smoker patients and $68.4 \%$ received $\leq 9$ years education. Additionally, $\sim 73.5 \%$ patients or one of their family members presented with dysplastic nevus. According to the TNM staging system (14), 22 patients were in stage I, 16 were in stage II and 14 were in stage III/IV. Among these patients, there were 32 patients with lymph node metastasis and 23 patients with poor differentiation. The total rate of positive bFGF staining in melanoma was $59.6 \%(31 / 52)$. The rate of positive bFGF staining in patients with melanoma with lymph node metastasis was significantly higher compared with patients without lymph node metastasis ( $\mathrm{P}=0.00006$; Table IV; Fig. 4).

\section{Discussion}

Invasion and metastasis are the essential biological characteristics of malignant tumors, as well as the primary causes of cancer-associated mortality (15). Tumor angiogenesis and lymph node metastasis are the prerequisite of malignant tumor invasion and metastasis (15). Therefore, the aim of antitumor therapy is to inhibit vascular endothelial cell proliferation and lymph node metastasis (16).

As a cell mitogen and angiogenic factor, bFGF is a member of the fibroblast growth factor family (17). The bFGF is able to promote malignant tumor invasion and metastasis by secreting a number of proteolytic enzymes and collagenase, including matrix metalloproteinase-14 (15).

The present study revealed that the level of bFGF expression was markedly increased in patients with NSCLC. The rate of positive bFGF staining was significantly higher in low-differentiated NSCLC compared with moderate/well NSCLC (Table I). In addition, the rate of positive bFGF staining was significantly higher in patients with NSCLC with lymph node metastasis compared with in patients with NSCLC without lymph node metastasis. These results indicated that the differentiation stage and lymph node metastasis had effects on the level of bFGF expression, which was consistent with a previous study (18). A 
Table III. bFGF protein expression in patients with breast cancer.

\begin{tabular}{|c|c|c|c|c|c|c|c|}
\hline \multirow[b]{2}{*}{ Variable } & \multirow[b]{2}{*}{$\mathrm{n}$} & \multicolumn{4}{|c|}{ bFGF expression, $\mathrm{n}$} & \multirow{2}{*}{$\begin{array}{l}\text { Positive } \\
\text { rate, } \%\end{array}$} & \multirow[b]{2}{*}{ P-value ${ }^{a}$} \\
\hline & & - & + & ++ & +++ & & \\
\hline Differentiation & & & & & & & 0.31327 \\
\hline Poor & 118 & 30 & 41 & 34 & 13 & 74.6 & \\
\hline Moderate/well & 88 & 28 & 30 & 25 & 5 & 68.2 & \\
\hline TNM stage & & & & & & & 0.00001 \\
\hline I & 59 & 27 & 17 & 10 & 5 & 54.2 & \\
\hline II & 48 & 18 & 15 & 9 & 6 & 62.5 & \\
\hline III/IV & 99 & 13 & 22 & 38 & 26 & 86.8 & \\
\hline Lymph node metastasis & & & & & & & $<0.00001$ \\
\hline Yes & 134 & 118 & 19 & 25 & 32 & 88.1 & \\
\hline No & 72 & 30 & 9 & 5 & 0 & 41.7 & \\
\hline
\end{tabular}

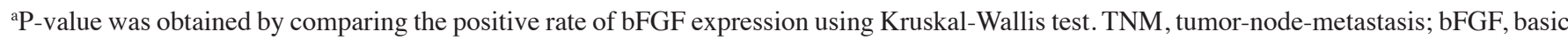
fibroblastic growth factor.

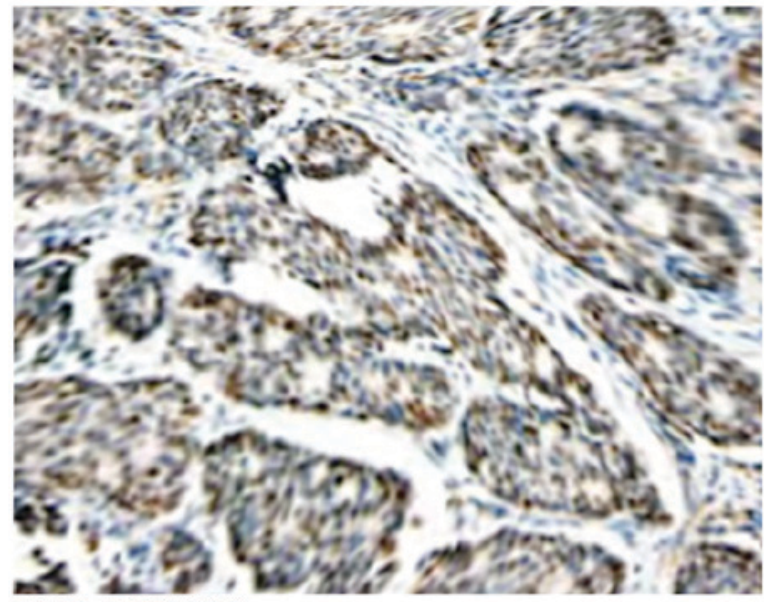

TNM III/IV

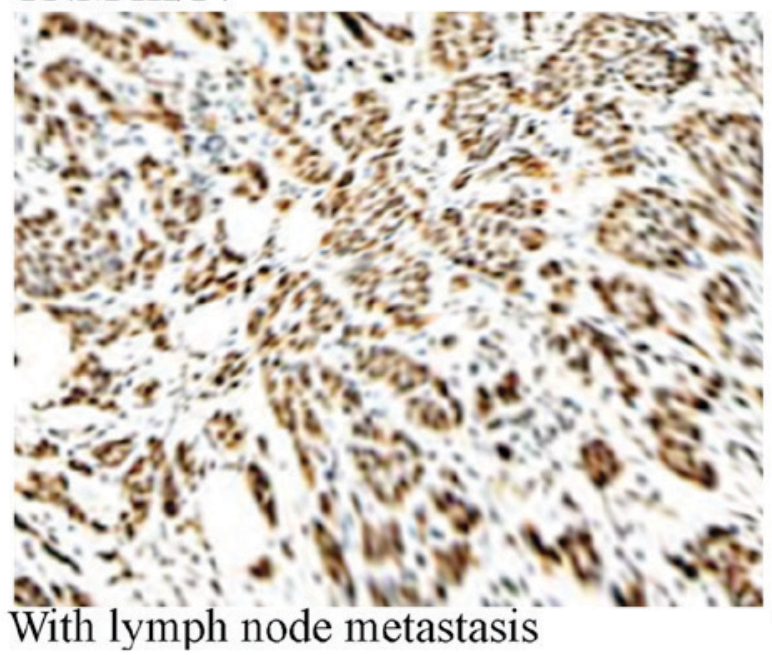

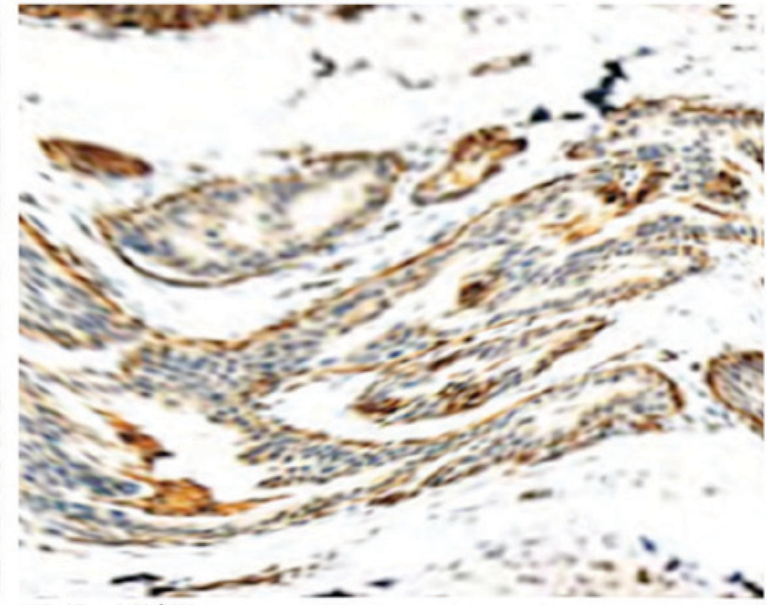

TNM I/II

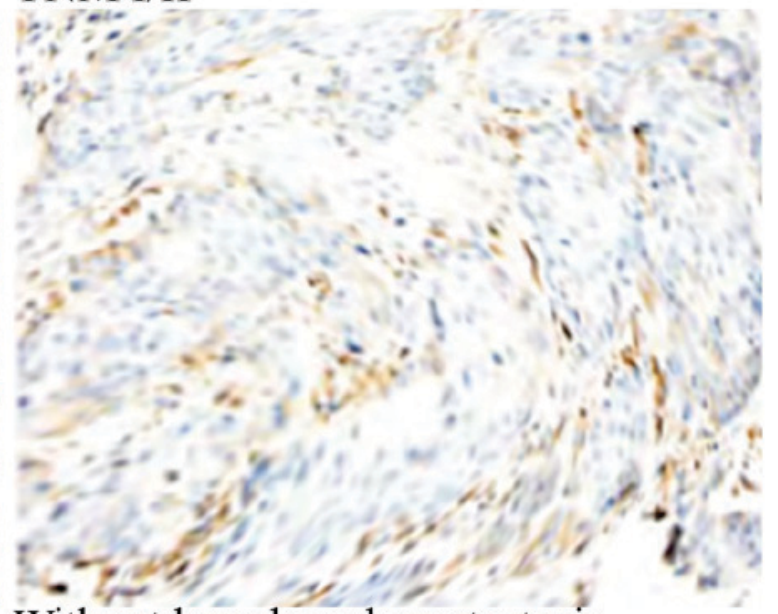

Without lymph node metastasis

Figure 3. Representative image of immunohistochemical staining of basic fibroblastic growth factor in in tumor tissues obtained from patients with breast cancer. TNM, tumor-node-metastasis (magnification, x100).

number of previous studies also reported that the expression of bFGF and FGFR was increased in advanced NSCLC cell lines compared with in normal cell lines $(11,12)$. Therefore, bFGF and its receptor may be novel targets for NSCLC treatment. 
Table IV. bFGF protein expression in patients with melanoma.

\begin{tabular}{|c|c|c|c|c|c|c|c|}
\hline \multirow[b]{2}{*}{ Variable } & \multirow[b]{2}{*}{$\mathrm{n}$} & \multicolumn{4}{|c|}{ bFGF expression, $n$} & \multirow{2}{*}{$\begin{array}{l}\text { Positive } \\
\text { rate, \% }\end{array}$} & \multirow[b]{2}{*}{ P-value } \\
\hline & & - & + & ++ & +++ & & \\
\hline Differentiation & & & & & & & 0.68627 \\
\hline Poor & 23 & 10 & 7 & 6 & 0 & 56.5 & \\
\hline Moderate/well & 29 & 11 & 6 & 10 & 2 & 62.1 & \\
\hline TNM stage & & & & & & & 0.90318 \\
\hline I & 22 & 9 & 7 & 5 & 1 & 59.1 & \\
\hline II & 16 & 7 & 4 & 4 & 1 & 56.3 & \\
\hline III/IV & 14 & 5 & 3 & 4 & 2 & 64.2 & \\
\hline Lymph node metastasis & & & & & & & 0.00006 \\
\hline Yes & 32 & 6 & 7 & 14 & 5 & 81.3 & \\
\hline No & 20 & 15 & 3 & 2 & 0 & 25.0 & \\
\hline
\end{tabular}

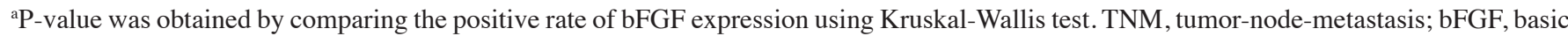
fibroblastic growth factor.
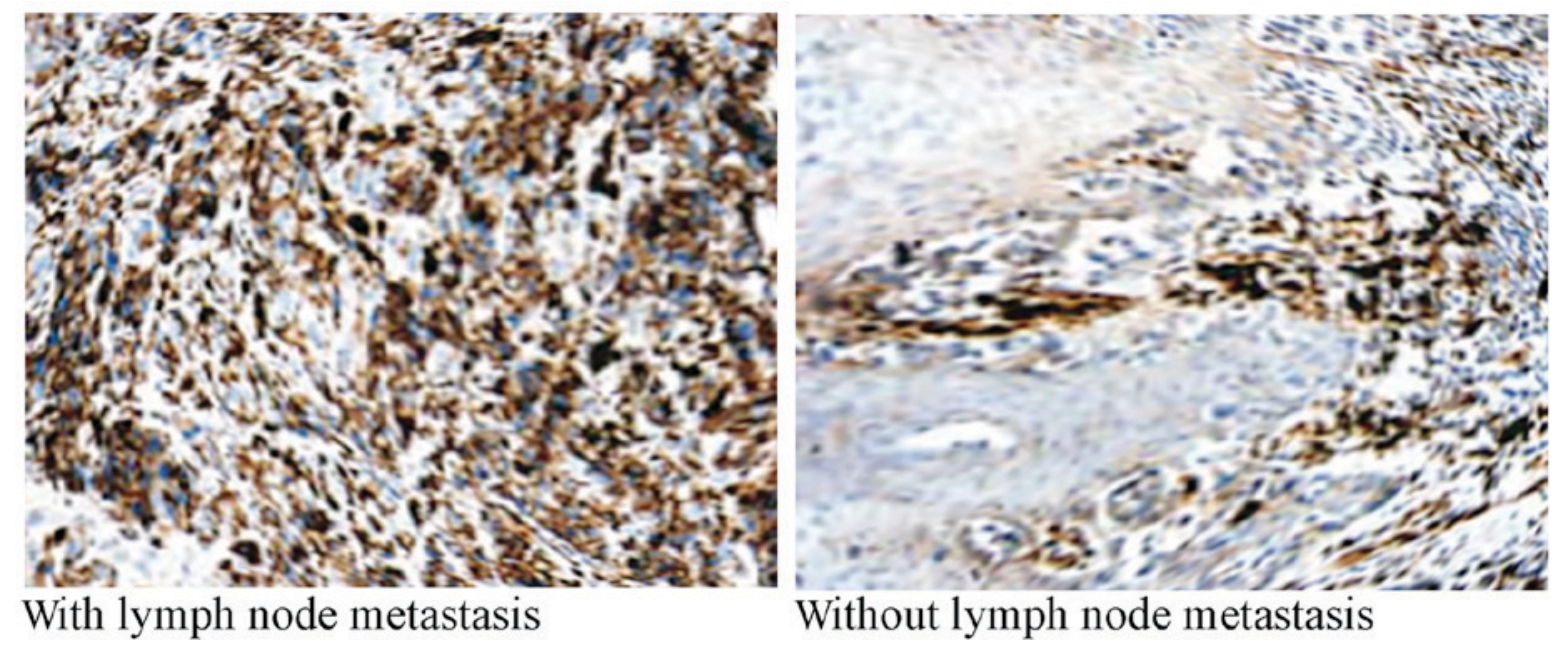

Figure 4. Representative image of immunohistochemical staining of basic fibroblastic growth factor in in tumor tissues obtained from patients with melanoma (magnification, x100).

The present study also revealed that the level of bFGF expression in colon cancer tumor tissues was increased, and the rate of positive bFGF staining in patients with colon cancer with lymph node metastasis was significantly increased compared with that of patients without lymph node metastasis. This finding indicated that bFGF may serve a role in enabling colon cancer metastasis, which was similar to the findings of a previous study (19). In addition, there was a non-significant increased rate of positive bFGF staining in tissues obtained from patients with poorly differentiated colon cancer compared with tissues from patients with moderately/well-differentiated colon cancer (65.0 vs. 55.2\%), which may indicate that bFGF may be involved in promoting angiogenesis and proliferation of cells in poorly-differentiated colon cancer. Landriscina et al (20) also revealed that the bFGF tumour concentration was not associated with the stage of disease. Therefore, bFGF may be a potential biomarker for colon cancer diagnosis and prognosis.
In the present study, immunohistochemical results indicated that the rate of positive bFGF staining in breast cancer is $71.8 \%$, which was similar with the results of a previous long-term follow-up study (21). This finding indicated that the high level of bFGF expression was associated with breast cancer. In the present study, the rate of positive bFGF staining was demonstrated to be significantly higher in patients with stage III/IV breast cancer (86.8\%) compared with stage I-II breast cancer (57.9\%). In addition, there was a significantly increased rate of positive bFGF staining in breast cancer patients with lymph node metastasis compared with patients without lymph node metastasis, which indicated that the high level of bFGF expression was associated with tumor invasion $(22,23)$. A previous study also reported that patients with breast cancer without lymph node metastasis and positive bFGF expression exhibited a longer median overall survival time than patients with lymph node metastasis (21). Therefore, monitoring the change in bFGF expression may be helpful 
for clinicians and patients with breast cancer to predict the efficacy of treatment.

Previous studies reported that the rate of positive bFGF expression in patients with melanoma was $30-90 \%(24,25)$. In the present study, the rate of positive bFGF staining in patients with melanoma was demonstrated to be $59.6 \%$. Straume and Akslen (24) reported that the high level of bFGF expression in melanoma may be associated with the high density of small vessels in melanoma cell. Compared with patients without lymph node metastasis, patients with lymph node metastasis had significantly increased rate of positive bFGF staining. This may be due to the expression level of bFGF being increased along with an increase in degree of malignancy of melanoma cells. Birck et al (25) indicated that the level of bFGF expression in melanoma was increased by $36 \%$ compared with the level in premalignant lesion (nevi). These results demonstrated that bFGF was an important factor involved in melanoma genesis and growth.

The present study had several limitations. The sample size was relatively small. Therefore, large-scale studies are required to validate the results. All of the patients were female, so whether the conclusion of the study can be applied to males was unclear. Additionally, only four types of malignant tumors were investigated, so whether the level of bFGF protein can be a potential biomarker for diagnosing other types of female-specific cancer, including cervical cancer and ovarian cancer, requires future studies.

In conclusion, the present study indicated that the level of bFGF expression was associated with malignant tumor growth and metastasis. bFGF protein may be a potential biomarker for diagnosing malignant tumor metastasis in women. The present results may be helpful for the clinical application of targeted anti-bFGF antibody and FGFR antagonists.

\section{References}

1. Attoub S, Arafat K, Gélaude A, Al Sultan MA, Bracke M, Collin P, Takahashi T, Adrian TE and De Wever O: Frondoside a suppressive effects on lung cancer survival, tumor growth, angiogenesis, invasion, and metastasis. PLoS One 8: e53087, 2013.

2. Chao Y, Li CP, Chau GY, Chen CP, King KL, Lui WY, Yen SH, Chang FY, Chan WK and Lee SD: Prognostic significance of vascular endothelial growth factor, basic fibroblast growth factor, and angiogenin in patients with resectable hepatocellular carcinoma after surgery. Ann Surg Oncol 10: 355-362, 2003

3. Gospodarowicz D: Fibroblast growth factor. Chemical structure and biologic function. Clin Orthop Rel Res 257: 231-248, 1990.

4. Montero A, Okada Y, Tomita M, Ito M, Tsurukami H, Nakamura T, Doetschman T, Coffin JD and Hurley MM: Disruption of the fibroblast growth factor-2 gene results in decreased bone mass and bone formation. J Clin Invest 105: 1085-1093, 2000.

5. Wei X: Research advances of basic fibroblast growth factor in tissue repair. Orthop J Chin 19: 1108-1110, 2011.

6. Presta M,Dell'Era P, Mitola S, Moroni E, Ronca R and Rusnati M Fibroblast growth factor/fibroblast growth factor receptor system in angiogenesis. Cytokine Growth Factor Rev 16: 159-178, 2005.

7. Luo CF, Hong HL, Lu YL, Wang H and Liu MQ: Expression of bFGF and PTEN in cervical carcinoma and their clinical significance. Zhonghua Zhong Liu Za Zhi 32: 533-538, 2010 (In Chinese).

8. Trojan L, Thomas D, Knoll T, Grobholz R, Alken P and Michel MS: Expression of pro-angiogenic growth factors VEGF, EGF and bFGF and their topographical relation to neovascularisation in prostate cancer. Urol Res 32: 97-1031, 2004.
9. Cucina A, Borrelli V, Lucarelli M, Sterpetti AV, Cavallaro A, Strom R, Santoro-D'Angelo L and Scarpa S: Autocrine production of basic fibroblast growth factor translated from novel synthesized mRNA mediates thrombin-induced mitogenesis in smooth muscle cells. Cell Biochem Funct 20: 39-46, 2002.

10. Polnaszek N, Kwabi-Addo B, Peterson LE, Ozen M, Greenberg NM, Ortega S, Basilico C and Ittmann M: Fibroblast growth factor 2 promotes tumor progression in an autochthonous mouse model of prostate cancer. Cancer Res 63: 5754-5760, 2003.

11. Coldren CD, Helfrich BA, Witta SE, Sugita M, Lapadat R, Zeng C, Barón A, Franklin WA, Hirsch FR, Geraci MW and Bunn PA Jr: Baseline gene expression predicts sensitivity to gefitinib in non-small cell lung cancer cell lines. Mol Cancer Res 4: 521-528, 2006

12. Marek L, Ware KE, Fritzsche A, Hercule P, Helton WR, Smith JE, McDermott LA, Coldren CD, Nemenoff RA, Merrick DT, et al: Fibroblast growth factor (FGF) and FGF receptor-mediated autocrine signaling in non-small-cell lung cancer cells. Mol Pharmacol 75: 196-207, 2009

13. Xu TM, Xin Y, Cui MH, Jiang X and Gu LP: Inhibitory effect of ginsenoside $\mathrm{Rg} 3$ combined with cyclophosphamide on growth and angiogenesis of ovarian cancer. Chin Med J (Engl) 120: 584-588, 2007.

14. Sobin LH, Hermanek P and Hutter RV: TNM classification of malignant tumors. A comparison between the new (1987) and the old editions. Cancer 61: 2310-2314, 1988.

15. Song S, Wientjes MG, Gan Y and Au JL: Fibroblast growth factors: An epigenetic mechanism of broad spectrum resistance to anticancer drugs. Proc Natl Acad Sci USA 97: 8658-8663, 2000.

16. Amino N, Ideyama Y, Yamano M, Kuromitsu S, Tajinda K, Samizu K, Hisamichi H, Matsuhisa A, Shirasuna K, Kudoh M and Shibasaki M: YM-359445, an orally bioavailable vascular endothelial growth factor receptor-2 tyrosine kinase inhibitor, has highly potent antitumor activity against established tumors. Clin Cancer Res 12: 1630-1638, 2006.

17. Keegan K, Johnson DE, Williams LT and Hayman MJ: Isolation of an additional member of the fibroblast growth factor receptor family, FGFR-3. Proc Natl Acad Sci USA 88: 1095-1099, 1991.

18. Joensuu H, Anttonen A, Eriksson M, Mäkitaro R, Alfthan H, Kinnula V and Leppä S: Soluble syndecan-1 and serum basic fibroblast growth factor are new prognostic factors in lung cancer. Cancer Res 62: 5210-5217, 2002.

19. Elagoz S, Egilmez R, Koyuncu A, Muslehiddinoglu A and Arici S: The intratumoral microvessel density and expression of bFGF and $\mathrm{nm} 23-\mathrm{H} 1$ in colorectal cancer. Pathol Oncol Res 12: 21-27, 2006.

20. Landriscina M, Cassano A, Ratto C, Longo R, Ippoliti M, Palazzotti B, Crucitti F and Barone C: Quantitative analysis of basic fibroblast growth factor and vascular endothelial growth factor in human colorectal cancer. Br J Cancer 78: 765-770, 1998.

21. Faridi A, Rudlowski C, Biesterfeld S, Schuh S, Rath W and Schröder W: Long-term follow-up and prognostic significance of angiogenic basic fibroblast growth factor (bFGF) expression in patients with breast cancer. Pathol Res Pract 198: 1-5, 2002.

22. Takeda M, Mikami T, Numata Y, Okamoto M and Okayasu I: Papillary thyroid carcinoma with heterotopic ossification is a special subtype with extensive progression. Am J Clin Pathol 139: 587-598, 2013.

23. Chikazawa M, Inoue K, Fukata S, Karashima T and Shuin T: Expression of angiogenesis-related genes regulates different steps in the process of tumor growth and metastasis in human urothelial cell carcinoma of the urinary bladder. Pathobiology 75 : 335-345, 2008.

24. Straume $\mathrm{O}$ and Akslen LA: Importance of vascular phenotype by basic fibroblast growth factor, and influence of the angiogenetic factors basic fibroblast growth factor/fibroblast growth factor receptor-1 and ephrin-A1/EphA2 on melanoma progression. Am J Pathol 160: 1009-1019, 2002.

25. Birck A, Kirkin AF, Zeuthen J and Hou-Jensen K: Expression of basic fibroblast growth factor and vascular endothelial growth factor in primary and metastatic melanoma from the same patients. Melanoma Res 9: 375-381, 1999. 